\title{
UNA APROXIMACIÓN GEOPOLÍTICA A LA POLÍTICA BINACIONAL DE SEGURIDAD fronteriza entre Colombia y Panamá
}

\author{
César Augusto Niño González* \\ Felipe Jaramillo Ruiz**
}

\section{Resumen}

La tradición geopolítica entre Colombia y Panamá se distancia de las aproximaciones clásicas a las relaciones internacionales. Las características geográficas de la región fronteriza brindan la posibilidad de ampliar el prisma teórico para analizar la manera como se regula el espacio limítrofe entre los Estados. A partir del caso de estudio Colombia-Panamá, el artículo evidencia los límites conceptuales de las principales aproximaciones geopolíticas. Así, propone desarrollar una agenda investigativa que se aleje de los presupuestos Estadocéntricos, conflictivos y expansivos que suelen dominar el estudio de la regulación territorial en las relaciones internacionales.
Palabras clave: geopolítica, política binacional de seguridad fronteriza, Colombia, Panamá, seguridad.

\section{A GEOPOLITICAL APPROACH TO THE BINATIONAL SECURITY BORDER POLICY BETWEEN COLOMBIA AND PANAMA}

\begin{abstract}
The geopolitical tradition between Colombia and Panama differs from the classical international relations approaches. The geographic characteristics of the border region offer a valuable opportunity to amplify the theoretical prism to analyze the way the border region
\end{abstract}

* PhD en Cuestiones Actuales del Derecho Español e Internacional, Universidad Alfonso X El Sabio de España. Profesor-investigador de la Escuela de Política y Relaciones Internacionales de la Universidad Sergio Arboleda, Bogotá (Colombia). [cesar.nino@usa.edu.co].

** Candidato a Doctor en Ciencia Política y Relaciones Internacionales, Graduate Institute of International and Development Studies. Profesor-investigador de la Escuela de Política y Relaciones Internacionales, Universidad Sergio Arboleda, Bogotá (Colombia). [felipe.jaramillo@usa.edu.co].

Recibido: 28 de febrero de 2018 / Modificado: 23 de julio de 2018 / Aceptado: 27 de julio de 2018.

Para citar este artículo

Niño, C. y Jaramillo Ruiz, F. (2018). Una aproximación geopolítica a la política binacional de seguridad fronteriza entre Colombia y Panamá. opera, 23, 81-96.

DoI: https://doi.org/10.18601/16578651.n23.06 
between states is regulated. By studying the Colombia-Panama case, the article evidences the conceptual limits of the main geopolitical approximations. In this sense, it proposes to develop an alternative geopolitical research agenda that breaks away from state-centric, expansive, and conflictive visions that have predominated in the research of the territorial regulation of international relations.

Key words: Geopolitics, binational border security policy, Colombia, Panama, security.

\section{INTRODUCCIÓN}

Las relaciones fronterizas colombo-panameñas presentan una serie de particularidades que las distinguen en términos geopolíticos. Primero, hasta el 3 de noviembre de 1903, el istmo de Panamá fue parte integral del territorio colombiano. Segundo, situaciones irregulares y asimétricas como las guerrillas, el narcotráfico, el terrorismo, el crimen organizado, el pandillismo, la trata de personas y los recursos multiplican las complicaciones fronterizas entre ambos Estados; al parecer, las amenazas y los problemas de seguridad en la zona de frontera tienden a ser cada vez más entrópicas. Tercero, sus territorios están separados por el Tapón del Darién, una barrera natural que alberga una extraordinaria biodiversidad y en la cual se encuentran las comarcas indígenas de Madugandí, Guna Yala, Wargandí y Emberá-Wounaan. Estas características hacen que las discusiones de geopolítica y seguridad de la zona fronteriza se distingan y alejen de las narrativas tradicionales de las relaciones internacionales.
El artículo evalúa la política binacional de seguridad fronteriza entre Colombia y Panamá, con el fin de contrastar las dinámicas geopolíticas del caso con las aproximaciones tradicionales al estudio de la geopolítica. Está dividido en cuatro secciones: en la primera se presentan los antecedentes del diálogo fronterizo entre Colombia y Panamá; más que un recuento histórico, en esta sección se identifican las particularidades geográficas, sociales y culturales que distinguen la zona fronteriza. En la segunda se discuten las principales tradiciones de la geopolítica clásica; el estudio se detiene para analizar las asimetrías conceptuales que limitan el entendimiento de las construcciones geopolíticas desde la periferia. Así, se sostiene que las principales ideas de los autores clásicos de la geopolítica tradicional, como Mackinder, Haushofer, Kristof, Kjellén, entre otros, sirvieron para responder a las problemáticas en contextos precisos de sus tiempos y lugares, pero que en términos disciplinares formaron un lastre que restringe la elucubración de teorías que sirvan para comprender con mayor precisión los obstáculos geopolíticos que se enfrentan en la zona fronteriza entre Panamá y Colombia.

En la tercera parte se presenta la metodología empleada para la elaboración del documento. Allí se advierte una serie de elementos fundamentales en su construcción que sirven de eje para el estudio. Posteriormente, el análisis sobre la política binacional de seguridad fronteriza toma un significante protagonismo porque es en los documentos oficiales donde se evidencia cómo el lastre Estado-céntrico, armamentista, hegemónico y expansivo de la geopolítica se traduce en asimetrías estructu- 
rales y problemas entre lo diseñado y la acción política en materia de seguridad fronteriza.

Con el caso planteado, esta investigación propone un distanciamiento de todo orden clásico de las principales tradiciones geopolíticas. Así, se ofrece una primera aproximación teórica a una geopolítica subalterna, la cual pretende ampliar la discusión sobre las dinámicas espaciales y geográficas en las relaciones internacionales. Bajo este prisma conceptual, se invita a desarrollar investigaciones que continúen formulando las bases para la comprensión de la geopolítica subalterna, en la cual las fronteras sean vistas como escenarios intermésticos ${ }^{1}$ de interacción entre múltiples actores, agendas e intereses.

\section{ANTECEDENTES DEL DIÁLOGO DE SEGURIDAD FRONTERIZO ENTRE COLOMBIA Y PANAMÁ}

Entablar un análisis sobre el diálogo de seguridad fronteriza entre Colombia y Panamá permite hacer una breve exploración alrededor de América Latina en dicha materia. Diversos han sido los factores que influyen para que se redefina la política de seguridad en América Latina, a partir de cuestiones relevantes en el contexto regional de la Guerra Fría, la Doctrina de Seguridad Nacional, e incluso, la proliferación de situaciones irregulares y asimétricas como las guerrillas, el narcotráfico, el terrorismo, el crimen organizado, el pandillismo, el tráfico ilegal de personas y recursos, y la tendencia, entre las décadas de 1960 y 1980 , a los golpes militares e interrupciones al orden democrático, entre otras (Amaris y Camacho, 2013). Los problemas y las amenazas a la seguridad se entienden como escenarios interdependientes, intermésticos y propiamente volátiles, que ponen en vilo la existencia del Estado o la circunstancialidad de los actores regulares. América Latina presenta una configuración irregular de la seguridad debido a la variedad de factores no convencionales que logran su vulneración.

Las relaciones colombo-panameñas alcanzan un punto neurálgico en la historia bilateral con la separación de Panamá en 1903. Desde este acontecimiento histórico, el diálogo político entre ambos Estados no tuvo mayores flujos sino hasta 1924 (Ministerio de Relaciones Exteriores, 1982), fecha en la cual se establecen relaciones diplomáticas oficialmente. No obstante, a pesar de la construcción paulatina de canales diplomáticos, la separación de Panamá se tornaría parte de la tradición geopolítica entre los dos Estados.

En la historia colombiana, la descripción de la separación se repartiría en dos principales narrativas. Algunos autores se enfocarían en el papel de Estados Unidos y su política imperialista (Fischer, 1998; Bergquist, 2004). Otros resaltarían las fallas del Gobierno colombiano, y sostenían que la pérdida se debió al abandono de Colombia, con implementación de un sistema centralista que desatendió las necesidades y aspiraciones de autonomía del istmo (Hinestrosa, 2004; Cavalier, 2003). Por su parte, en

1 Concepto acuñado por Bayless Manning (1977), que describe los asuntos que son "profunda e inseparablemente tanto internacionales como domésticos”. Suscrito en Capurganá, Chocó, el 10 de febrero de 2011. 
la historia de Panamá, el relato se enfocaría en los agravios causados por las políticas de Colombia y la necesidad imperiosa que impulsó la independencia del istmo (Araúz, 1980). En suma, la separación de Panamá marcaría un hito en las relaciones entre los Estados y se tornaría en una especie de memoria colectiva en la tradición geopolítica de la región.

Hacia 1990, Panamá suprime su ejército debido a la historia reciente de dictadura y golpe militar, situación que afectaría las dinámicas de la seguridad interna y externa hacia la configuración de instrumentos disuasivos contra actores armados (Selser, 1990). Según Robert C. Harding (2006), la frontera entre Colombia y Panamá es una de las más volátiles de América Latina, lo que ha suscitado lo que algunos llaman la remilitarización de las fuerzas de seguridad panameñas, en aras de reforzar la seguridad fronteriza. Así, la ausencia de un ejército panameńo es otra de las particularidades de la tradición geopolítica en la frontera entre los dos países.

En términos generales, las motivaciones políticas y estratégicas en materia de seguridad fronteriza estuvieron relegadas en las agendas bilaterales durante buena parte del siglo xx. De hecho, aquella cuestión sigue siendo una tarea pendiente a pesar de los avances bilaterales. Cuestiones como el conflicto armado colombiano, la ausencia institucional del Estado, y la proliferación de grupos armados en zona fronteriza han sido causas estructurales para la diversificación de actores y actividades delictivas (Cabrera, 2016). Con base en lo anterior, las relaciones fronterizas entre Panamá y Colombia se caracterizaron por la ausencia histórica de una política pública integral, transversal y constante por parte de Colombia. Este distanciamiento, sumado a la divergencia estratégica de los gobiernos, genera un lastre que hace que la dinámica fronteriza, desde el espectro colombiano, tenga un tinte pesimista y vulnerable (Molano y Zarama, 2016). Ante la ausencia de una política pública en términos fronterizos entre Colombia y Panamá, las dinámicas de las fronteras pasaron a ser reguladas por actores, agendas e intereses no estatales (Suman, 2007). Se tornaron puntos de convergencia y divergencia simultáneamente, en los cuales el epicentro de las disputas no gravita hacia preocupaciones de soberanía, sino que se conjugan una serie de intereses que afectan las relaciones entre los Estados.

La desconexión física y geográfica de Bogotá con el resto del territorio, así como la visión sesgada en cuestiones geopolíticas y de política exterior de las distintas administraciones, ha permitido que exista un desbordamiento de los fenómenos de violencia e inseguridad en las zonas fronterizas, en especial en la zona del gran arco de 266 kilómetros (Stone, 2011). Entre Colombia y Panamá existe una frontera terrestre cubierta por la selva espesa y adversidades topográficas, circunstancias que han sido excusa para la desconexión bilateral, la ausencia estatal y el quiebre de la carretera Panamericana en el Darién, ruta que atraviesa el continente. De tal manera, la frontera colombo-panameña, según la Defensoría del Pueblo (2017), es la más activa en la migración internacional irregular, es el paso natural de los migrantes que se dirigen a Estados Unidos y, al mismo tiempo, es por naturaleza una barrera natural.

Según lo anterior, la necesidad de tener herramientas plausibles para mitigar y contra- 
rrestar los problemas y las amenazas a la seguridad en la zona motivó a la construcción de un diálogo bilateral estratégico. En 1996, Colombia creó la Comisión Binacional Fronteriza (COMbifron) en conjunto con Ecuador, lo que representó un antecedente técnico y de alto gobierno para tratar los asuntos concernientes a la defensa y seguridad en la frontera, a la evaluación y supervisión en el cumplimiento de los compromisos militares y policiales entre ambas naciones, generar medidas de confianza mutua y fortalecer las relaciones entre las fuerzas públicas con el propósito de solucionar conjuntamente los problemas fronterizos (Fuentes, 2010). Sin embargo, solo hasta el 2003 se llevó a cabo la primera reunión de la Combifron entre Colombia y Panamá, en la que se acordó un trabajo conjunto y coordinado sobre asuntos fronterizos y la creación de un banco de datos con antecedentes delictivos y el perfil de personas en zonas aledańas.

Con ese primer antecedente, el inicio de una agenda bilateral de alto nivel en términos de seguridad fronteriza tomó periodicidad temática hasta el punto de crearse el Plan Binacional de Seguridad Fronteriza ${ }^{2}$ con el objetivo de tratar de afrontar las amenazas comunes y compartidas en la zona de frontera. Paralelo a lo anterior, en el año 2014 el Gobierno colombiano, a través del Consejo Nacional de Política Económica y Social (CONPES), emitió el Plan de Prosperidad para las Fronteras (CONPES 3805). Estos instrumentos tienen como objetivo principal entablar protocolos, acciones y mecanismos ágiles para contrarrestar cualquier impase o situación problemática o amenaza en la zona de frontera que ponga en riesgo la seguridad de alguna o de ambas naciones. En ese orden de ideas, la política fronteriza entre Colombia y Panamá surge de forma tardía y como una reacción a la presencia de intereses y actores no convencionales en el estudio de las relaciones internacionales.

\section{EL LASTRE DE LAS TRADICIONES GEOPOLÍTICAS}

En 1899, Rudolf Kjellén acuñó el término geopolítica para referirse a la relación entre la geografía y las condiciones económicas, sociales, culturales y territoriales de un Estado (Atkinson y Dodds, 2000). Con la formulación del concepto, Kjellén buscaba transmitir una sensación de novedad; el autor intentaba describir los desafíos que se desenlazarían con el inicio del siglo xx (Heffernan, 2000). En particular, a partir del darwinismo social, quería construir una forma objetiva para analizar la evolución del poder de los Estados.

Para Kjellén, tres características geopolíticas incidían en la formación y consolidación de los Estados: la localización, el tamaño territorial y la forma del territorio (Holdar, 1992). Estos distintivos geográficos no eran meramente descriptivos. Según Kjellén, en la contienda entre los grandes poderes, el Estado victorioso sería aquel que lograra una posición favorable en términos geopolíticos. Las potencias del sistema internacional serían aquellas que se

2 Suscrito en Capurganá, Chocó, el 10 de febrero de 2011. 
situaran en un punto geoestratégico frente a otros Estados, distantes de otros actores que amenazaran su seguridad, cuyo tamaño les permitiera una autosuficiencia en términos productivos, y que tuvieran un territorio concéntrico que facilitara la cohesión interna (Tunander, 2001). Por consiguiente, los postulados propuestos por Kjellén se volvieron una especie de manual para la conducción de la política exterior de las grandes potencias.

El concepto acuñado por Kjellén fue replicado por un gran número de autores, lo cual introdujo la geopolítica en el centro de los estudios de las relaciones internacionales. No obstante, la geopolítica no se convirtió en un cuerpo organizado y coherente de conocimiento. Surgieron una pluralidad de aproximaciones cuyo propósito consistía en examinar la compleja relación entre la geografía y la política desde escalas espaciales, tanto locales como globales (Kristof, 1960). A pesar de la multiplicidad de acercamientos, la geopolítica se posicionó como una ciencia dirigida a explorar los conflictos limítrofes y fronterizos entre los Estados. Así, marcó un hito en la forma en que la teoría se relacionaba con la práctica, en tanto que los estadistas incorporaron nociones espaciales para justificar políticas exteriores expansionistas (Murphy, 2004). Fuera de la esfera académica, el concepto tomó un tinte político más particular. Por ejemplo, Henry Kissinger y Zbigniew Brzezinski en Estados Unidos, por Valdimir Zhirinovsky y Alexandr Dugin en Rusia, e Yves Lacoste en Francia, formularon estrategias geopolíticas con un tinte ideológico conservador, el cuales se anclaba en ideas nacionalistas que propendían por la defensa, la seguridad y los intereses de las po- tencias mundiales (Bassin, 2004; Hyndman, 2004).

El contexto en el cual surgió la idea de la geopolítica trazó las líneas teóricas que definirían la disciplina. La naturaleza conflictiva que caracterizó el estudio de la geopolítica en el siglo xx reflejó la preocupación de los teóricos por explicar y entender las transformaciones políticas del sistema internacional al encontrarse frente a un espacio limitado (Deudney, 2000). Por ejemplo, en su obra magna, El pivote geográfico de la historia, de 1904, Halford Mackinder discutió el futuro de Europa ante el fin de la exploración geográfica y el desmantelamiento del modelo colonial. Para el autor, con el inicio del siglo xx, después de 400 años, el mapa del mundo se plasmaba con más exactitud que nunca, y se reducía así la posibilidad de descubrimientos dramáticos que ampliaran el espectro del conocimiento. Frente a esta realidad, la humanidad tendría que enfrentarse a un nuevo sistema político de magnitudes globales, en el cual los deseos de incrementar el poder no se verterían a espacios inexplorados, sino que se volcarían a espacios ocupados. Para Mackinder, este cambio en las relaciones internacionales conllevaría una lucha por el poder entre las grandes potencias (Mackinder, 2004).

En Alemania, la geopolítica sirvió para articular la preocupación por el aumento territorial de los Estados. Las escuelas de pensamiento alemanas, lideradas por Karl Haushofer, tornaron la geopolítica como instrumento para promover la expansión territorial (Bowman, 1942). El concepto de Raum, por ejemplo, subordinó la política a la geografía. Al concebir al Estado como un organismo, se promovió la 
lucha por el espacio vital de estos. Bajo esta perspectiva, la geografía pasó a instruir a la política y no viceversa. La geografía actuaba como una especie de fuerza natural que determinaba el comportamiento y las posibilidades de los Estados. Esta visión positivista que se impuso en los inicios del siglo xx desencadenaría la guerra entre las principales potencias europeas.

Según Ladis K. D. Kristof (1960), las principales tradiciones de la geopolítica han abandonado la idea de que el entorno geográfico determina las relaciones humanas. En otras palabras, el estudio de la política no mira el mapa para tratar de evidenciar cómo las fuerzas naturales obligan a la humanidad, pero sí para examinar cómo estas "recomiendan" ciertas acciones. Bajo esta óptica, la geopolítica no determina la política exterior de los Estados, pero son estos los que formulan sus preferencias y la geopolítica. Esta concepción es de suma importancia, en tanto expone el elemento político que direcciona la manera como los actores internacionales divisan sus límites y conciben el espacio.

Para muchos geógrafos, la geopolítica se tornó la base para estudios enigmáticos, oscuros y sesgados. En la disciplina de las Relaciones Internacionales, sin embargo, la geopolítica continuó siendo el foco de diversos debates. Para varios autores, la geopolítica ofrece una perspectiva privilegiada para examinar la realidad de la política mundial (Deudney, 2000). A pesar de la diversidad de propuestas, los artículos que incorporan una aproximación geopolítica tienden a compartir tres rasgos fundamentales. Primero, la mayoría de estudios adoptan una noción Estado-céntrica del sistema internacional. Segundo, la literatura suele enfocarse en los conflictos fronterizos entre los Estados. Tercero, se tiende a partir de una lógica expansiva, en la cual los Estados buscan incrementar su territorio. Así, las aproximaciones geopolíticas actuales continúan replicando las ideas de las relaciones internacionales bajo las cuales nació el concepto (Hyndman, 2004).

\section{METODOLOGÍA}

La metodología implementada en este artículo se basa en un estudio de caso. Para desarrollar la investigación se analizan documentos oficiales, académicos y periodísticos sobre los avances y la implementación del Plan Binacional de Seguridad Fronteriza como política pública. Como un estudio inductivo, se examinan los principales ejes y temáticas que se abordan en el Plan Binacional de Seguridad Fronteriza. Al yuxtaponer el análisis a la discusión teórica, se busca evidenciar las particularidades de la tradición geopolítica entre Panamá y Colombia.

En ese orden de ideas se plantea la pregunta: ¡cómo la geopolítica entre Colombia y Panamá se diferencia de las tradiciones clásicas de esta disciplina? Para resolver el anterior interrogante se considera cómo la accidentalidad geográfica, los imaginarios colectivos, la aparición de actores irregulares y la noción de identidad son variables relevantes al desarrollar un análisis sobre la seguridad y la geopolítica contemporáneas (Dodds y Atkinson, 2000). Asimismo, incluso al examinar las políticas públicas, se debe considerar la pluralidad de intereses y actores que participan en las construcciones geopolíticas. Es decir, se debe 
partir de una visión interméstica de las relaciones internacionales, las cuales rechazan las nociones unitarias de los Estados y propagan aproximaciones dicotómicas que separan el ámbito doméstico del internacional.

Aunque el análisis propuesto mantiene cierta afinidad con las características que han marcado los estudios de la geopolítica, se distancia de los mismos en tanto que propone un análisis que considera los factores interdependientes, intermésticos y propiamente volátiles que ponen en vilo la seguridad y la cooperación entre los Estados. Así, la política exterior está íntimamente relacionada con la existencia de actores no convencionales que transforman la manera como los Estados actúan en su propio territorio y frente a los demás Estados. En el caso concreto, se examina cómo el conflicto armado colombiano, la ausencia institucional del Estado, el fortalecimiento de movimientos ambientales y la proliferación de grupos armados en zona fronteriza han afectado las políticas de frontera entre Colombia y Panamá.

\section{POLÍTICA BINACIONAL DE SEGURIDAD FRONTERIZA: MÁS ALLÁ DE LA GEOGRAFÍA}

La situación fronteriza entre Colombia y Panamá se caracteriza por la volatilidad, la asimetría, el espacio vacío, la convergencia de grupos irregulares y los flujos de migración irregular, entre otras. En efecto, la frontera y su situación son el reflejo de la denominada "sexta generación de la guerra”, la cual hace énfasis en advertir que las manifestaciones de violencia, y la nula participación estatal como garante y dispositivo preponderante en el uso de la fuerza constituyen una degeneración conceptual de la seguridad (Nińo, 2017), un contexto plausible para determinar las condiciones fronterizas entre ambos Estados.

Según el CONPES 3805, la propuesta de la política pública para las fronteras de Colombia es fomentar la equidad social, la productividad y la reducción de las brechas, con el fin de mejorar la calidad de vida de los habitantes desde un enfoque diferencial, territorial, étnico y cultural (CONPES 3805, 2014). Dicho documento expresa de manera alentadora una serie de baterías institucionales para afrontar los asuntos de las fronteras, pero el primer gran inconveniente es que el texto no logra particularizar la naturaleza propia de cada zona de frontera, y no todas presentan las mismas condiciones geopolíticas y de seguridad.

Colombia se ha convertido en punto de tránsito para miles de migrantes irregulares provenientes de Latinoamérica, África y Asia. Esto motiva la construcción de una oportunidad para la delincuencia común y las bandas criminales en el área. En esa misma lógica, las fronteras del Estado desembocan con aproximadamente 76 pasos ilegales que hacen de Colombia un paso obligado para conectar con destinos internacionales (Palma, 2015), y la zona del Darién, conocida por su posición estratégica en cuanto a la movilidad marítima intercontinental y por sus recursos hídricos, mineros, de biodiversidad es, paradójicamente, una de las regiones con mayores niveles de pobreza, abandono estatal, desplazamiento forzado y área de confluencia criminal (Alameda, 2009). En esencia, es una región atractiva 
geoestratégicamente para operadores de seguridad oficial y no convencional.

Al respecto, con el Plan Binacional de Seguridad Fronteriza ambos gobiernos acordaron coordinar operaciones en el Darién, que es el único enlace terrestre entre América Central y América del Sur (Stone, 2011). En términos geopolíticos, la región Urabá-Darién está conformada por diferentes tipos de formaciones biofísicas que forjan un complejo andamiaje espacial, cartográfico y climatológico (Alameda, 2009) ${ }^{3}$. De tal manera, lo anterior permite una predisposición geográfica para el ejercicio de distintos poderes confluyentes y, simultáneamente, establece zonas productivas y actividades extractivas que se relacionan de manera directa con dinámicas económicas tanto legales como ilícitas y subterráneas.

En efecto, ambas administraciones asimilan la región como un reto estratégico por su geografía, pero continúan dejando al margen cuestiones relevantes como la fenomenología de los múltiples actores. Más allá del crimen y de los pasos ilegales que confluyen en la zona, los Estados obvian las construcciones sociales y medioambientales en la frontera. Dos variables que conforman una geopolítica subalterna y que se distancian de las clásicas de la geopolítica.
En ese sentido, el Estado colombiano ha señalado que los problemas de seguridad y violencia se deben exclusivamente a factores relacionados con grupos criminales, y ha pasado por alto otras variables que se advertían en el CONPES 3805, lo que significa una desconexión estratégica entre las políticas públicas y los planes de desarrollo para zonas en particular. La presencia del Estado en el desarrollo de políticas de seguridad para la zona fronteriza, en especial entre Colombia y Panamá, es asumida con la presencia de la fuerza pública, situación errónea que mal entiende las múltiples causas y desvirtúa la noción integral del concepto de seguridad. En esta oportunidad, la interacción del eje en mención tiene que ver con dinámicas y lógicas Estado-céntricas exclusivamente, un desacierto preliminar al momento de enfrentar la irregularidad más allá del componente geográfico.

Si bien el Plan ha logrado contener ciertos flujos de tráfico de drogas que intentan pasar hacia el norte del continente ${ }^{4}$, los problemas de seguridad en la región se gestan, no por las dinámicas rivales entre fuerzas estatales y grupos armados ilegales, sino por la lucha territorial, espacial y comercial de los grupos ilegales allí presentes. Durante los primeros meses del ańo 2018 ha habido más de cinco enfrentamientos

3 La región del Urabá-Darién está conformada por los municipios de Riosucio, Turbo, Unguía, Acandí, El Carmen del Darién, Mutatá, Chigorodó, Carepa, Apardadó, Necoclí, San Juan de Urabá, Arboletes y San Pedro de Urabá, en la frontera colombiana. En la frontera panameña está conformada por los corregimientos Agua Fría, Camoganti, Garachiné, La Palma, Jaqué, Puerto Piña, Chepigana, Río Congo, Río Iglesias, Río Congo Arriba, Sambú, Setegantí, Taimatí, Tucutí, Cucunatí, Santa Fe, Boca de Cupe, Paya, Pinogana, Púcuro, Metetí, El Real de Santa María, Yape y Yaviza Wargandi.

4 El 16 de enero de 2018, en una operación militar y policial entre Colombia y Panamá, se incautaron 1.496 kilos de coca avaluada en más de 16 millones de dólares, pertenecientes al Negro Perea, del Clan del Golfo (El Tiempo, 2018). 
entre grupos, con decenas de muertos civiles. En especial, se ha visto una creciente presencia de los grupos armados organizados, como el Clan del Golfo, las Águilas Negras, el Ejército de Liberación Nacional (ELN), las disidencias de las FARC y el Ejército Popular de Liberación (EPL).

La multidimensionalidad de la seguridad y la geopolítica en este caso específico lleva a reflexiones en torno a las comunidades que se encuentran inmersas en la violencia y la criminalidad. En ambos lados de la frontera, los derechos de los indígenas y de los afrodescendientes se han visto vulnerados porque sus tierras fueron declaradas baldíos por el Estado y entregadas en concesión a multinacionales (Ramírez, 2016).

Lo anterior significa, entonces, que la seguridad está más allá de una lógica militar, y la geopolítica de una exclusivamente geográfica. En ese orden de ideas, la construcción negativa sobre las implicaciones de la política pública en materia de geopolítica entre ambas naciones ha resultado en desencadenantes que se convierten en amenazas y problemas para ambos Estados. La entropía de los resultados que se muestran en la figura 1 es consecuencia de la falta de noción integral sobre la geopolítica, o resultado de la visión tradicional de la seguridad y la geografía, dinámicas que por

FIGURA 1. CONSECUENCIAS NEGATIVAS DEL ABANDONO ESTATAL

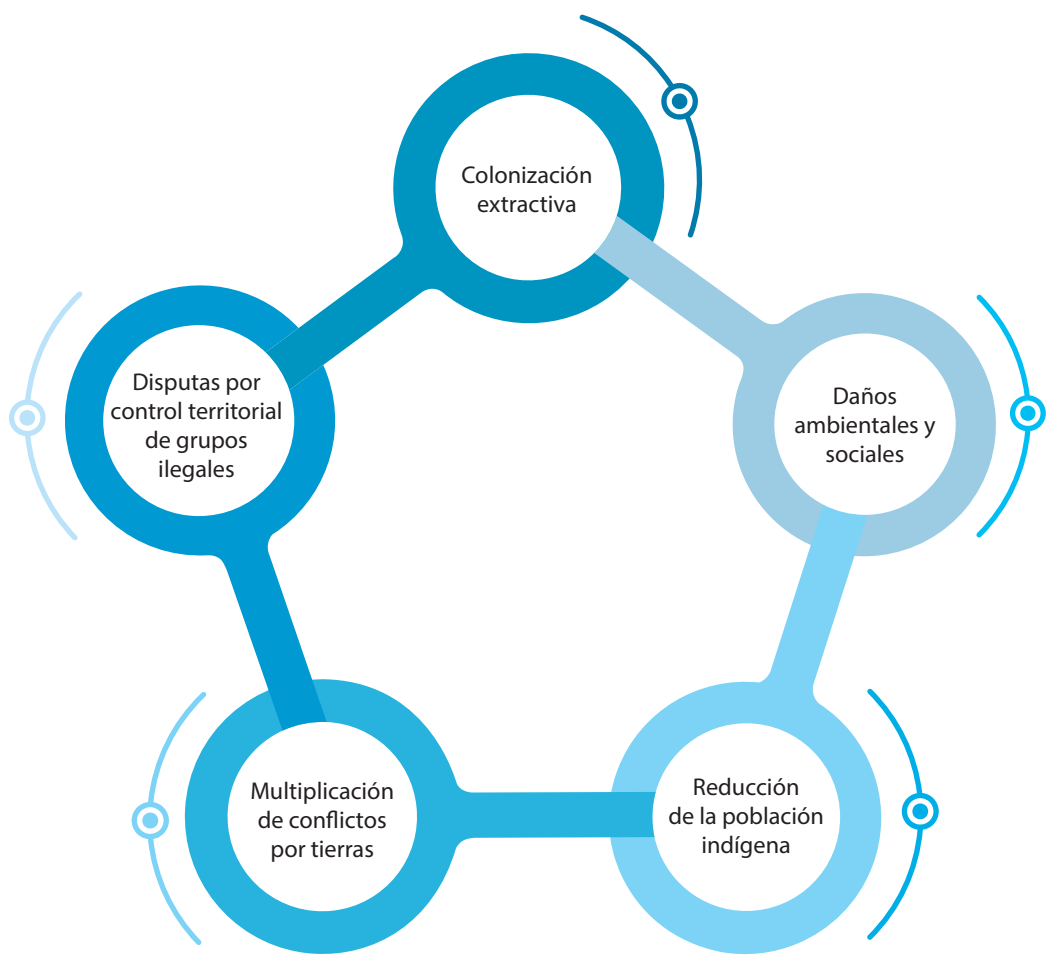

Fuente: elaboración propia con base en Ramírez (2016). 
tradición conceptual y por naturaleza interméstica se escapan de las lógicas hegemónicas e imperantes en las agendas de política pública y académicas. Por tal razón, la ampliación e identidad de una construcción geopolítica hacia particularidades subalternas son de vital importancia para los análisis más precisos y la elaboración de soluciones más integrales. Los espacios vacíos entre la terminología imperante y la realidad periférica son escenarios plausibles para el acentuamiento de los conflictos.

Aunque las consideraciones ambientales han desempeñado un papel crucial en la geopolítica colombo-panameña (Miller, 2014), estas no han sido desarrolladas a profundidad en la política pública colombo-panameña. Por ejemplo, aunque el CONPEs 3805 de 2014 establece que el Estado colombiano debe definir los criterios de sostenibilidad ambiental en la actividad minera, el análisis del resumen de los recursos por entidad, vigencias 20142021, demuestra que mientras los recursos del Ministerio de Defensa alcanzan los 1'201.911 millones de pesos, solo se destinan 60 millones para las actividades del Ministerio de Ambiente y Desarrollo Sostenible (CONPEs 3805, 2014). Así, las preocupaciones ambientales aún se encuentran al margen de la geopolítica fronteriza. Además, se mantiene una visión de explotación de los recursos naturales que carece de una proyección más holística que regule los temas ambientales. En suma, en la agenda bilateral los asuntos ambientales se escapan de todo orden estratégico y no se tiene en cuenta su deterioro. Una ausencia que muestra serias debilidades institucionales.

Ante esta ausencia de una geopolítica ambiental clara entre Colombia y Panamá, otros actores pasan a jugar un papel más relevante.
Por ejemplo, Miller (2014) demuestra que grupos ambientalistas han logrado combatir la narrativa de progreso y desarrollo que se trató de imponer desde los Estados. En particular, el autor demuestra que, a pesar de la voluntad política de construir la autopista Panamericana, los esfuerzos transnacionales de actores no estatales presionaron para que no se construyera la vía. De esta manera, conmemora la no construcción de la autopista como una de las mayores victorias ambientales de los actores no convencionales de las relaciones internacionales. Estos lograron frenar los objetivos de integración hemisférica por medio de la autopista Panamericana. En otras palabras, los actores principales de la geopolítica no fueron los Estados fronterizos que propendieron por la seguridad militar de su territorio, sino actores de la sociedad civil que posicionaron el medio ambiente en la agenda internacional.

En efecto, según Daniel Suman (2007), los grupos ambientales desempeñaron un rol fundamental en la decisión del Programa Ambiental de las Naciones Unidas, el cual en el 2007 le otorgó estatus de patrimonio mundial a la región del Darién (United Nations Environmental Programme, 2018). Sin embargo, al examinar la victoria de los grupos ambientales, se debe tener en cuenta que la región continúa aislada de los centros de poder de Colombia y Panamá. Así, ante la deficiencia de servicios públicos, transporte e infraestructura, florecen grupos al margen de la ley que avanzan en la colonización de la zona e impulsan la deforestación (Girot, 2002). Esto ha llevado a una crisis humanitaria para las poblaciones indígenas y afrocolombianas, las cuales padecen de altos indicadores de pobreza y de necesidades básicas insatisfechas (Ortiz, 2004). Asimismo, se ha 
evidenciado que las dinámicas de la violencia han generado un escenario propicio para el surgimiento de grandes terratenientes, los cuales se han beneficiado del conflicto armado para incrementar su poder en la zona.

Los grupos ambientales no son el único actor no estatal que ha jugado un papel fundamental en la geopolítica entre Colombia y Panamá. Las comunidades indígenas y afrocolombianas también se han posicionado como actores relevantes en el estudio de las relaciones fronterizas entre los Estados (Suman, 2007). Por ejemplo, debido a la presión de las comunidades indígenas, en 1983 el Gobierno de Panamá creó dos regiones autónomas en la región del Darién: las comarcas de Cémaco y Sambú (Sánchez y De Gerdes, 2018). De la misma manera, el Gobierno de Colombia reconoció los resguardos indígenas Emberá y Wounaan a partir de la Constitución de 1991 y la promulgación de la Ley 160 de 1994, las cuales reconocieron las demandas territoriales de estas comunidades en el Bajo Atrato y la costa Pacífica del departamento del Chocó. Por su parte, las comunidades afro también han logrado la protección de sus derechos culturales y étnicos. A modo de ejemplo, a las comunidades afrocolombianas desde 1993 se les otorga la posibilidad de obtener títulos de propiedad colectivos, los cuales son inalienables e imprescriptibles (Hoffmann, 1999).

En el territorio colombiano, las presiones ejercidas por las comunidades indígenas y afrocolombianas han suscitado la resistencia de grupos paramilitares auspiciados por grandes terratenientes, latifundistas, la agroindustria y actores comerciales. Ante la violencia armada en la frontera, el departamento del Chocó se ha convertido en uno de los principales centros de desplazamiento forzado hacia Panamá y al interior de Colombia. Según William Villa y Juan Houghton, "la territorialidad privada de corte paraestatal y contraestatal (insurgente) se ha venido sobreponiendo a las territorialidades étnicas que venían en procesos emergentes como resultado del proceso constituyente del 91, marcadas en este caso por los intereses de la coca y el control de rutas militares" (Villa y Houghton, 2005, p. 45).

Frente a los desafíos ambientales, los actores no estatales han articulado sus esfuerzos como grupos de presión, entablando litigios estratégicos que salvaguarden el medio ambiente y los derechos de las comunidades indígenas y afrodescendientes. Por ejemplo, por medio de una tutela, las comunidades étnicas que habitan la cuenca del río Atrato lograron que la Corte Constitucional de Colombia condenara la conducta omisiva del Estado, e instó a este a "proveer una respuesta institucional idónea, articulada, coordinada y efectiva para enfrentar los múltiples problemas históricos, socioculturales, ambientales y humanitarios que aquejan a la región y que en los últimos años se han visto agravados por la realización de actividades intensivas de minería ilegal" (Corte Constitucional, 2016).

Ante lo expuesto, se evidencia que las características ambientales y socioculturales de la región afectan la forma como los diversos actores definen las dinámicas geopolíticas de la región del Darién. En el contexto de la frontera colombo-panameña, los actores estatales no son los únicos que inciden en la forma como se regula el espacio limítrofe entre los dos Estados.

Al yuxtaponer las tradiciones clásicas de la geopolítica con el caso de estudio, salta a la 
vista la ausencia de herramientas conceptuales para comprender la realidad geográfica entre Colombia y Panamá. La narrativa predominante que presenta a los Estados como actores unitarios, en búsqueda constante de la expansión territorial, y cuya principal amenaza son los otros Estados se distancia drásticamente de la geopolítica subalterna de la región. Las relaciones colombo-panameñas no obedecen a la lógica que caracterizó los orígenes del estudio de la geopolítica. No obstante, en el estudio de las relaciones internacionales, las aproximaciones predominantes continúan incorporando nociones Estado-céntricas que forman una especie de lastre que ancla el estudio de la geopolítica. La formulación de una perspectiva geopolítica subalterna requiere emancipar la disciplina de este lastre.

Como posibles agendas de investigación a futuro, se invita a investigar y a ahondar en las posibles tradiciones geopolíticas en la región. El uso del plural es importante para la incorporación de las nuevas maneras de entender los problemas contemporáneos relevantes a la geopolítica. Por ejemplo, el análisis del caso propuesto invita a repensar las nociones geopolíticas de los actores involucrados, como son: Estado, grupos de presión, grupos de interés, comunidades nativas, actores armados ilegales, flujos de comunicación y de tráfico, y variables sociales, económicas, culturales, historias convergentes y divergentes, entre otras.

\section{CONCLUSIÓN}

Al contrastar los postulados tradicionales de la geopolítica con el caso de estudio, se expone la falta de herramientas conceptuales para explicar situaciones que no se acoplen a las narrativas Estado-céntricas, hegemónicas y expansivas que predominan en las investigaciones geopolíticas. En la zona fronteriza entre Colombia y Panamá convergen una serie de intereses, agendas y actores. La región se ha tornado un frente de batalla entre agentes estatales y poderes económicos que desean impulsar la globalización y la integración hemisférica, y grupos de presión que propenden por la conservación ambiental y el respeto de las comunidades locales. Grupos que han logrado incluso moldear de alguna manera la agenda, usado instrumentos de diplomacia paralela y, en oportunidades, partícipes de la inclusión temática de cuestiones no tradicionales en el radar del Estado.

No obstante, el presente documento muestra la necesidad de alejarse de las tradicionales configuraciones terminológicas sobre la geopolítica para entender las particularidades referentes a cada contexto, en esta oportunidad, entre la frontera colombo-panameña. Las cuestiones intermésticas, la diversidad fenomenológica y las condiciones fronterizas invitan a reformular viejos arquetipos académicos y estratégicos. La frontera entre Colombia y Panamá, junto a la elaboración de la política binacional de seguridad fronteriza, parecieran presentar brechas asimétricas constantemente. La lectura estatal sobre los problemas que afronta la zona parece distanciarse de la realidad que manifiestan otros actores involucrados. Dicho distanciamiento deja por fuera actores y fenómenos que dejan fisuras institucionales y agravan aún más los problemas más allá de los asuntos geográficos. 


\section{REFERENCIAS}

Alameda, S. (2009). Tapón del Darién: el dilema del desarrollo. Bogotá: Universidad Nacional de Colombia.

Amaris, A. y Camacho, A. (2013). Análisis de la seguridad interna y externa en Panamá: su posición con respecto a la seguridad regional. Bogotá: Friedrich Ebert Stiftung.

Araúz, C. A. (1980). Historia de la independencia de Panamá: sus antecedentes y sus causas, 1821-1903. Panamá: Academia Panameña de la Historia.

Atkinson, D. y Dodds, K. (2000). Introduction to geopolitical traditions: A century of political thought. En D. Atkinson y K. Dodds (eds.). Geopolitical traditions: A century of geopolitical thought (pp. 1-24). London: Routledge.

Bassin, M. (2004). The two faces of contemporary geopolitics. Progress in Human Geography, 28 (5), 620-626.

Bergquist, C. (2004). Panamá y los orígenes sociales del imperialismo norteamericano. En Colombia y Panamá: La metamorfosis de la nación en el siglo XX (pp. 291-306). Bogotá: Universidad Nacional de Colombia.

Bowman, I. (1942). Geography vs. geopolitics. Geographical Review 32 (4), 646-658.

Cabrera, I. (2016). Conflicto armado, criminalidad y violencia en la frontera colombo-panameña: elementos críticos para buscar una transición. En A. Molano (ed.). Las fronteras en Colombia como zonas estratégicas: análisis y perspectivas (pp. 221-245). Bogotá: Instituto de Ciencia Política "Hernán Echavarría Olózaga" / Fundación Konrad Adenauer.

Cavalier, G. (2003). Centenario de Panamá: una historia de la separación de Colombia en 1903. Bogotá: Universidad Externado de Colombia.
CONPES 3805 (2014). Prosperidad para las Fronteras de Colombia. Bogotá: Departamento Nacional de Planeación.

Corte Constitucional. Sentencia T-622 de 2016.

Defensoría del Pueblo (2017). Sobre las zonas de frontera. Bogotá: Defensoría del Pueblo.

Deudney, D. (2000). Geopolitics as a theory: Historical security materialism. European Journal of International Relations, 6 (1), 77-107.

Dodds, K. y Atkinson, D. (2000). Geopolitical traditions: A century of geopolitical thought. London and New York: Routledge.

El Tiempo. Judicial. 16 de enero de 2018. Recuperado de http://www.eltiempo.com/justicia/conflictoy-narcotrafico/incautan-cocaina-del-clan-usugaen-panama- 171588

Figueroa, A. (2004). El departamento colombiano de Panamá a fines del siglo diecinueve e inicios de la vigésima centuria. En H. Bonilla y G. Montañez (eds.). Colombia y Panamá: la metamorfosis de la nación en el siglo XX (pp. 93-125). Bogotá: Universidad Nacional de Colombia.

Fischer, T. (1998). Antes de la separación de Panamá: la guerra de los mil días, el contexto internacional y el canal. Anuario Colombiano de Historia Social y de la Cultura 25 (pp. 73-108). Bogotá: Universidad Nacional de Colombia.

Fuentes, S. (2010). La Comisión de Vecindad de Ecuador y Colombia: la delgada línea entre conflicto y la cooperación (Análisis 2002-2009). Quito: FLACsO.

Girot, P. O. (2002). The Darién region between Colombia and Panama: Gap or seal? (172-183). En Zarsky, L. Human Rights \& The Environment: Conflicts and norms in a globalizing world.

Harding, R. C. (2006). The History of Panama. London: Greenwood Press.

Heffernan, M. (2000). Fin de siecle, fun du monde? On the origins of European geopolitics, 1890-1920. 
En Dodds, K. y Atkinson, D. (eds.). Geopolitical traditions: A century of geopolitical thought (pp. 27-50). London: Routledge.

Hinestrosa, F. A. (2004). Panamá no nos la quitarion: la peridió el abandono de Colombia. Revista de Economía Institucional, 6 (10), 223-227.

Hoffmann, O. (1999). La titulación de territorios colectivos de las comunidades negras en Colombia: Entre inovaciones y contradicciones. En W. Assies, A. Hoekema y ven der Harr, G. (eds.). El reto de la diversidad: pueblos indígenas y reforma del estado en América Latina. México: El Colegio de Michoacán.

Holdar, S. (1992). The ideal state and the power of geography: The life-work of Rudolf Kjellén. Political Geography, 11 (3), 307-323.

Hyndman, J. (2004). Revisiting Mackinder 1904-2004. The Geographical Journal, 170 (4), 380-383.

Kristof, L. K. D. (1960). The origins and evolution of geopolitics. The Journal of Conflict Resolution, 4 (1), 15-51.

Mackinder, H. (2004). The geographical pivot of history (1904). The Geographical Journal, 170 (4), 298-321.

Manning, B. (1977). The Congress, the Executive and Intermestic Affairs: Three Proposals. Foreign Affairs, 55 (2), 306-324.

Miller, S. W. (2014). Minding the gap: PanAmericanism's highway, American environmentalism, and remembering the failure to close the Darién Gap Environmental History, 1-28.

Ministerio de Relaciones Exteriores (1982). Acta Tripartita sobre iniciaciones de relaciones diplomáticas y límites con Panamá. En Arreglo de límites entre la República de Colombia y la República de Panamá (pp. 25-29). Bogotá: Ministerio de Relaciones Exteriores.
Molano, A. y Zarama, F. (2016). Fronteras: gobernanza, sensibilidad y vulnerabilidad. En A. Molano (ed.). Fronteras en Colombia como zonas estratégicas: análisis y perspectivas, de 17-47. Bogotá: Instituto de Ciencia Política "Hernán Echavarría Olózaga” / Fundación Konrad Adenauer Stiftung.

Murphy, A. (2004). Is there a politics to geopolitics? Introduction. Progress in Human Geography, 28 (5), 619-640.

Niño, C. (2017). La sexta generación de la guerra: entre degeneraciones y violencias en la seguridad internacional. En A. Castillo y C. Niño (eds.). Nociones sobre seguridad y paz en las relaciones internacionales contemporáneas (pp. 33-49). Bogotá: Ediciones UsTA.

Ortiz, C. M. (2004). Colonización y violencia en la frontera con Panamá: Urabá y el Darién de 1950 a 1990. En H. Bonilla y G. Montańez (eds.). Colombia y Panamá: la metamorfosis de la nación en el siglo XX (pp. 381-412). Bogotá: Universidad Nacional de Colombia.

Palma, M. (2015). Tráfico de migrantes en Colombia: radiografía de un fenómeno en ascenso. Razón Pública. Recuperado de https://www.razonpublica.com/index.php/econom-y-sociedadtemas-29/8552-tr\%C3\%A1 fico-de-migrantes-en-colombia-radiograf\%C3\%ADa-de-unfen\%C3\%B3meno-en-ascenso.html

Ramírez, S. (2016). La frontera colombo-panameña: un drama humanitario. Razón Pública. Recuperado de .https://razonpublica.com/index. php/internacional-temas-32/9448-la-fronteracolombo-paname\%C3\%B1a-un-drama-humanitario.html 
Sánchez, K. E. y De Gerdes, M. (2018). Escuchemos a las Autoridades Emberá-Wounaan. Recuperado de http://www.binal.ac.pa/pa/panel/choco/sp/ autoridades.php

Selser, G. (1990). Panamá: la supresión de las Fuerzas de Defensa. Secuencia, 175-192.

Stone, H. (2011). Colombia, Panama Sign Border Security Pact. Recuperado de https://www.insightcrime. org/news/analysis/colombia-panama-sign-border-security-pact/

Suman, D. (2007). Globalization and the Pan-American highway: Concerns for the Panama-Colombia Border region of Darién-Chocó and its peoples. The University fo Miami Inter-American Law Review, 38 (3), 549-614.
Tunander, O. (2001). Wedish-German geopolitics for a new century: Rudolf Kjellén's 'The State as a Living Organism'. Review of International Studies, 27 (3), 451-463.

United Nations Environmental Programme (2018). World Heritage Site: Darién National Park. Recuperado de http://www.unep-wcmc.org/protected_areas/data/wh/darien.html.

Villa, W. y Houghton, J. (2005). Violencia politica contra los pueblos indigenas en Colombia 1974-2004. Bogotá: CECOIN. 